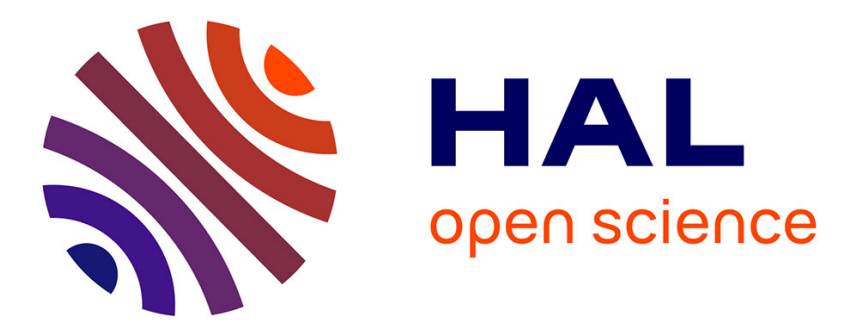

\title{
Organic optoelectronic devices-flexibility versus performance
}

Mohamad Chakaroun, A. El Amrani, Bruno Lucas, Bernard Ratier, Matt

Aldissi

\section{- To cite this version:}

Mohamad Chakaroun, A. El Amrani, Bruno Lucas, Bernard Ratier, Matt Aldissi. Organic optoelectronic devices-flexibility versus performance. European Physical Journal: Applied Physics, 2010, 51 (3), pp.33206. 10.1051/epjap/2010108 . hal-00618488

\section{HAL Id: hal-00618488 \\ https://hal.science/hal-00618488}

Submitted on 2 Sep 2011

HAL is a multi-disciplinary open access archive for the deposit and dissemination of scientific research documents, whether they are published or not. The documents may come from teaching and research institutions in France or abroad, or from public or private research centers.
L'archive ouverte pluridisciplinaire HAL, est destinée au dépôt et à la diffusion de documents scientifiques de niveau recherche, publiés ou non, émanant des établissements d'enseignement et de recherche français ou étrangers, des laboratoires publics ou privés. 


\title{
Organic optoelectronic devices-flexibility versus performance
}

\author{
M. Chakaroun, A. El Amrani, *B. Lucas, B. Ratier and M. Aldissi, \\ XLIM UMR 6172 - Université de Limoges/CNRS \\ 123 avenue Albert Thomas - 87060 Limoges Cedex, France \\ *Corresponding author: e-mail:bruno.lucas@unilim.fr
}

\begin{abstract}
In this paper, we discuss the effect of flexible substrates on the characteristics of two organic optoelectronic devices, namely P3HT:PCBM-based photovoltaic bulk heterojunctions and pentacene-based phototransistors. In addition, we have developed anode materials deposited by ion beam sputtering, a technique which satisfies the low temperature deposition requirements associated with the use of plastic substrates. The anode materials consisted of indium tin oxide (ITO) and ITO/metal/ITO tri-layers. The use of tri-layer anodes in P3HT:PCBM-based solar cells resulted in an increase in the fill factor and the power conversion efficiency reached a value of $2 \%$ with an $\operatorname{ITO}(70 \mathrm{~nm}) / \operatorname{Ag}(14 \mathrm{~nm}) / \mathrm{ITO}(70 \mathrm{~nm})$ anode deposited on a polyphthalate carbonate substrate. In the case of phototransistors, a photosensitivity of $1.610^{4}$ under illumination at 365 $\mathrm{nm}$ (with a power intensity of $7 \mathrm{~mW} / \mathrm{cm}^{2}$ ) was obtained in the off-state of the transistor. We have fine-tuned the anode structure and deposition/annealing conditions towards flexible organic devices and optimal device characteristics.
\end{abstract}

Keywords: Flexible substrate, Tri-layer transparent electrodes, Ion beam sputtering, Organic solar cells, Organic phototransistor.

\section{Introduction}

Many applications require the use of a transparent conductive oxide on flexible substrates, particularly organic optoelectronic components such as light-emitting diodes, photovoltaic cells and field-effect transistors. Indium tin oxide (ITO) is one of the most used oxides because of its low resistivity $\left(10^{-3}-10^{-4} \Omega . c m\right.$ depending on the deposition method used), and high transparency in the visible ( $80 \%$ to $90 \%$ between $400 \mathrm{~nm}$ and $800 \mathrm{~nm}$ ). Various techniques are used to deposit ITO films on plastic substrates such as pulsed-laser deposition (PLD) [1,2], magnetron sputtering $[3,4]$ and ion beam sputtering (IBS) [5,6], techniques which enable deposition at low 
temperatures (or room temperature). Most of the organic substrates deteriorate rapidly and lose their flexibility at deposition/annealing temperatures higher than $100^{\circ} \mathrm{C}$. However, ITO films deposited at low temperatures and without annealing do not yield polycrystalline layers which results in high resistivity ITO. To improve the crystallinity and electrical properties of ITO deposited on polymeric substrates, various solutions can be contemplated: either perform an ion beam assisted treatment during the ITO film growth (DIBS-Dual Ion Beam Sputtering) technology [7], or deposit ITO on a $\mathrm{ZnO}[8,9]$ or $\mathrm{SiO}_{2}$ [10] buffer layers, or replace ITO by an ITO/metal/ITO tri-layer anode [11].

The most successful organic photovoltaic devices use the soluble fullerene derivative phenylC61-butyric acid methyl ester (PCBM) as an electron acceptor and the semiconducting polymer poly(3-hexylthiophene) (P3HT) as an electron donor [12-14]. There is great interest in P3HT:PCBM photovoltaic devices because theoretical studies have predicted an external efficiency of 11\% [15]. Kim et al [16] reported P3HT:PCBM-based organic solar cells with a power efficiency in excess of $6 \%$ (measured under AM1.5 with an intensity of $100 \mathrm{~mW} / \mathrm{cm}^{2}$ ). Recently[17], it has been reported that poly[4,8-bis-substituted-benzo[1,2-b:4,5-b0]dithiophene2,6-diyl-alt-4-substituted-thieno[3, 4-b]thiophene-2,6-diyl]- based solar cells have a power conversion efficiency as high as $6.77 \%$ (certified by the National Renewable Energy Laboratory).

A great deal of work has also been reported in the area of organic phototransistors [18-20] including few recent papers on flexible phototransistors using poly(ethersulfone) substrates [21, 22]. Chung et al. [21] reported a two-terminal phototransistor based on 2,6-di(naphthalene-2-yl)9,10-bis(triisopropylsilylethynyl)anthracene single crystals as the active layer showing output/transfer characteristics with an on/off ratio of $510^{2}$ under blue illumination (at $470 \mathrm{~nm}$ ). Kwon et al. [22] fabricated a phototransistor based on 6,13bis(triisopropylsilylethynyl)pentacene which had a weak photo-response of approximately 5 with a halogen lamp $\left(15 \mathrm{~mW} / \mathrm{cm}^{2}\right)$. In fact, phototransistors are interesting for their use as switches, amplifiers, detection circuits or sensors of ultra sensitive image.

We have developed several anode materials that are suitable for flexible organic optoelectronic devices including ITO and ITO/metal/ITO tri-layers where the metal consisted of silver (Ag) or gold (Au). In this paper, we present our results on the use of ITO and ITO/Ag/ITO tri-layer electrodes deposited by IBS on polyphthalate carbonate (PPC) substrates for organic photovoltaic cells and on polyethylene terephtalate (PET) substrates for organic phototransistors. First, the electrical and optical properties of ITO and ITO/Ag/ITO tri-layers are discussed, followed by a discussion of device characteristics. 


\section{Experimental}

As mentioned above, IBS was used for the deposition of the anode materials. The technique consists of sputtering a target by an ion beam and the consecutive deposition on a substrate. The pressure in the vacuum chamber was maintained at $5.10^{-6}$ mbar. The targets were bombarded by argon ions accelerated at $6 \mathrm{keV}$ with a current density of $1 \mathrm{~mA} / \mathrm{cm}^{2}$ [9]. The Ag films were deposited on the ITO layer without heating the substrate during film growth and with a deposition rate of $0.6 \mathrm{~nm} / \mathrm{s}$. The thickness of Ag and ITO layers was controlled by a quartz crystal monitor. The different layers were characterized by electrical conductivity measurements (or sheet resistance with an experimental error of $\mathbf{\Omega} / \square$ ) using the four -point-probe method, and by optical transmittance in the visible using a SAFAS200 spectrophotometer.

The solar cells were fabricated using the following structure: anode/PEDOT/P3HT:PCBM/Al. A 30 nm-thick hole transport layer of poly(3,4ethylenedioxythiophene)-poly(styrenesulfonate) (PEDOT-PSS Baytron PH from HC Starck), which also prevents oxygen diffusion from ITO into the active layer [10], was deposited by spin coating on PPC substrates. The active layer was prepared as follows: $30 \mathrm{mg}$ P3HT (Aldrich: regioregular polymer with an average molecular weight, $\mathrm{Mw}=87 \mathrm{~kg} / \mathrm{mol}$ ) were dissolved in $1 \mathrm{~mL}$ of chlorobenzene, stirred on a hot plate at $80^{\circ} \mathrm{C}$ for 30 minutes, then added to a "solution" of $24 \mathrm{mg}$ PCBM (Aldrich) in 1mL of chlorobenzene which had been ultrasonicated for 30 minutes. Subsequently, the blend solution was filtered $(0.2 \mu \mathrm{m})$ and stirred for 10 minutes at $50^{\circ} \mathrm{C}$ in a nitrogen-filled glove box. The P3HT:PCBM ratio used was 1:0.8 weight\%. The thickness of the P3HT:PCBM layer of all samples in this study was maintained at approximately $100 \mathrm{~nm}$. This was followed by evaporation of a $100 \mathrm{~nm}$-thick aluminum (Al) cathode onto the surface of the active layer. The devices were then annealed at $100^{\circ} \mathrm{C}$ for 10 minutes. The tests were carried out under an equivalent AM 1.5 illumination with an intensity of $100 \mathrm{~mW} . \mathrm{cm}^{-2}$.

The flexible transistors were fabricated with pentacene as the active layer in "top-contact" geometry. First, we deposited a 150 nm-thick ITO layer on a $50 \mu$ m-thick PET substrate as the gate electrode. A $1 \mu$ m-thick polymethylmethacrylate (PMMA) layer was then deposited by spin-coating onto the ITO electrode as the dielectric layer, followed by the deposition of a 50 nm-thick pentacene film by thermal evaporation. The drain and source electrodes were made up of a thin gold layer (approximately $50 \mathrm{~nm}$ ) by vacuum evaporation through a mask. The length and width of the channel are $50 \mu \mathrm{m}$ and $4 \mathrm{~mm}$ respectively. All the devices were tested at room temperature. The characteristics of the transistor were investigated using a computer-controlled 4200 SMU Keithley equipment. A UV lamp (model B 100 AP UVP, emission centered at 365 
$\mathrm{nm}$, power of $7 \mathrm{~mW} / \mathrm{cm}^{2}$ ) positioned at $25 \mathrm{~cm}$ from the transistor active layer was used in an "on top" illumination mode.

\section{Results and discussion}

\subsection{Performance of flexible organic photovoltaic cells}

For this study, we have used the optimized IBS deposition process of the anode [23] in conjunction with a flexible substrate (PPC or PET) for device fabrication and characterization. Electrical and optical properties of the electrodes are summarized in Table 1 . The sheet resistance $(\mathrm{R} \square)$ reaches its lowest value of $6.5 \Omega / \square$ for $\operatorname{ITO}(70 \mathrm{~nm}) / \operatorname{Ag}(14 \mathrm{~nm}) / \operatorname{ITO}(70 \mathrm{~nm})$. However, the transmission is poor (68\% at 550nm) due to the Ag layer.

We have fabricated solar cells on PPC using two anodes having an almost identical thickness for comparison purposes: ITO (150nm) and ITO(70nm)/Ag(14nm)/ITO(70nm) (total thickness of $154 \mathrm{~nm})$. The $\mathrm{J}(\mathrm{V})$ characteristics under $100 \mathrm{~mW} / \mathrm{cm}^{2}$ illumination are shown in Figure 1 and Table 2. The results show that as the series resistance (Rs) decreases, the shunt resistance (Rsh) (and consequently the fill factor (FF)) increases for an $\operatorname{ITO}(70 \mathrm{~nm}) / \mathrm{Ag}(14 \mathrm{~nm}) / \mathrm{ITO}(70 \mathrm{~nm})$ anode because of its low sheet resistance $(6.5 \Omega / \square)$. Moreover a low Rs is advantageous for charge collection and transport preventing charge accumulation in the device.

IPCE (incident photon-to-current efficiency) defined as the number of electrons generated by light in the external circuit divided by the number of incident photons, is plotted in Figure 2. The simultaneous measurements of the anode transmission and the IPCE spectra show that the best contribution to photocurrent generation is in the 450-620 nm region, which corresponds to the maximum absorption of P3HT:PCBM. This constitutes a good match between its absorption and anode transmission which is also maximum in this region. Moreover, the power conversion efficiency obtained with the ITO/Ag/ITO anode is higher than the one obtained with ITO only, correlated to an increase of current density (from $3.33 \mathrm{~mA} / \mathrm{cm}^{2}$ to $9.58 \mathrm{~mA} / \mathrm{cm}^{2}$ ) and open-circuit voltage (from $0.39 \mathrm{~V}$ to $0.51 \mathrm{~V}$ ). The short circuit current increases by more than twofold while the fill factor increases from 0.35 to 0.39 . The significant improvement in the power conversion efficiency $(0.5 \%$ to $2 \%)$ is mainly due to the low sheet resistance of the ITO(70nm)/Ag(14nm)/ITO(70nm) anode in addition to the good match of its optical characteristics with those of the active layer as mentioned above. The obtained power conversion efficiency (2\%) is comparable to other reports in the literature [24-26]. 


\subsection{Performance of flexible organic phototransistors}

The output characteristics of the pentacene-based flexible OTFT tested in the dark are given in Figure 3. The maximum on/off current ratio is approximately $710^{5}\left(\mathrm{I}_{\mathrm{off}} \approx 10^{-12} \mathrm{~A}\right.$ and $\mathrm{I}_{\mathrm{on}} \approx 7$ $10^{-7} \mathrm{~A}$ for $\mathrm{V}_{\mathrm{gs}}=-50 \mathrm{~V}$ and $\mathrm{V}_{\mathrm{ds}}=-30 \mathrm{~V}$ ). A slight decrease in the drain current due to a bias stress effect can be noticed when the drain voltage increases. This behavior is associated with a shift in the threshold voltage without modifying the carrier mobility [27]. The plot of $\sqrt{-\mathrm{I}_{\mathrm{ds}}}=\mathrm{f}\left(\mathrm{V}_{\mathrm{gs}}\right)$ at $V_{\mathrm{ds}}=-30 \mathrm{~V}$ is shown in Figure $4 \mathrm{a}$ from which we determined the mobility $(\mu)$ in the saturation regime using the equation: $\mathrm{I}_{\mathrm{ds}}^{\mathrm{sat}}=\frac{\mathrm{WC} \mu}{2 \mathrm{~L}}\left(\mathrm{~V}_{\mathrm{gs}}-\mathrm{V}_{\mathrm{T}}\right)^{2}$ [28], where $\mathrm{L}$ and $\mathrm{W}$ are the length and width of the channel respectively, $C_{i}$ is the insulator capacitance per surface unit $\left(C_{i}=2.3 \mathrm{nF} / \mathrm{cm}^{2}\right.$ for 1 $\mu \mathrm{m}$ of PMMA and $\varepsilon \approx 2.6$ ), and $\mathrm{V}_{\mathrm{T}}$ is the threshold voltage. The mobility and threshold voltage values obtained in the dark are $10^{-2} \mathrm{~cm}^{2} \mathrm{~V}^{-1} \mathrm{~s}^{-1}$ and $17 \mathrm{~V}$ respectively.

We examined the static behavior of this transistor under UV illumination at $365 \mathrm{~nm}$ (with a power of $7 \mathrm{~mW} / \mathrm{cm}^{2}$ ). The dark and "on top" illumination transfer characteristics given in Figure 4, illustrate clearly the effect of illumination. These characteristics show a strong increase in the drain current under illumination due to photogeneration of electron-hole pairs in the active layer of the transistor. Photoexcitation at $365 \mathrm{~nm}$ results in the generation of free charge carriers without changing their mobility (Fig. 4a). Thus, the threshold voltage necessary to reach the accumulation regime decreases under illumination. We calculated the increase in the number of charge carriers per surface unit upon illumination using the relation: $\Delta N=\frac{C_{i} \Delta V_{T}}{e}$ where $C_{i}$ is the capacitance per surface unit of the dielectric layer, e is the elementary charge and $\Delta \mathrm{V}_{\mathrm{T}}$ is the threshold voltage shift, $\left(\Delta \mathrm{V}_{\mathrm{T}}=9 \mathrm{~V}, \mathrm{~V}_{\mathrm{T}}=17 \mathrm{~V}\right.$ in the dark and $\mathrm{V}_{\mathrm{T}}=8 \mathrm{~V}$ upon illumination $)$. We achieved a $\Delta \mathrm{N}$ of approximately $10^{11} \mathrm{~cm}^{-2}$.

A maximum $\mathrm{I}_{\mathrm{ds}(\mathrm{illum})} / \mathrm{I}_{\mathrm{ds}(\text { dark })}$ ratio of approximately $210^{4}$ is observed in the sub-threshold regime (off-state) as shown in Figure 4b. Moreover, the current gain at $\mathrm{V}_{\mathrm{gs}}=0 \mathrm{~V}$ is approximately $210^{3}$, which is higher than that obtained by other groups [21, 22]. When one of the two gates is turned off (i.e., $\mathrm{V}_{\mathrm{gs}}=0 \mathrm{~V}$ or without photoexcitation), the effect of the other gate is maximized. For example, the on/off ratio is much higher at $\mathrm{V}_{\mathrm{gs}}=-30 \mathrm{~V}$ without illumination ( $\mathrm{I}_{\text {on }} / \mathrm{I}_{\mathrm{off}} \approx 10^{5}$ in the dark and $\approx 100$ under illumination), while the $\mathrm{I}_{\mathrm{ds}(\mathrm{illum})} / \mathrm{I}_{\mathrm{ds}(\mathrm{dark})}$ ratio in the accumulation regime $\left(\mathrm{V}_{\mathrm{gs}}<-10 \mathrm{~V}\right)$ is much lower than the one obtained at $\mathrm{V}_{\mathrm{gs}}=0 \mathrm{~V}$. The dependence of photosensitivity $\mathrm{P}\left(\mathrm{P}=\mathrm{I}_{\mathrm{ds}(\mathrm{illum})}-\mathrm{I}_{\mathrm{ds}(\mathrm{dark})} / \mathrm{I}_{\mathrm{ds}(\mathrm{dark})}\right)$ on the gate voltage is shown in Figure 5. P exhibits a maximum value of $1.610^{4}$ at $\mathrm{V}_{\mathrm{gs}}=-7.5 \mathrm{~V}$ (flat-band voltage) and decreases with the increase in the absolute gate voltage. This is due to the fact that current 
amplification in the dark is higher than that of the light-induced current. We also notice a high photosensitivity $\left(1.510^{3}\right)$ at $\mathrm{V}_{\mathrm{gs}}=0 \mathrm{~V}$, which suggests that our transistors could find use in applications such as two-terminal photodetectors or current amplifiers under illumination.

We investigated the dynamic characteristics of the OTFT under illumination at $\mathrm{V}_{\mathrm{gs}}=0 \mathrm{~V}$ and at different $\mathrm{V}_{\mathrm{ds}}$ values (from $-30 \mathrm{~V}$ to $-200 \mathrm{~V}$ ). Figure 6 shows two types of profile during the rise time, which corresponds to the optical excitation time (60 s), and the decay time to the initial state. These decay and rise processes depend on carrier recombination and generation and on the minority carrier lifetime [29]. When the pentacene is illuminated, the photocarrier generation rate is proportional to the flow of incident photons. At first, electron and hole densities increase quickly, and the number of created pairs is much higher than the number of recombinations. After a few seconds, the recombination rate increases and becomes non negligible relative to the generation rate of pairs, and finally an equilibrium regime is reached. This regime is obtained rapidly when the transit time of majority carriers is high (for $V_{d s}=-30 \mathrm{~V}$ ) because recombinations are favored. When the light is switched off (after $60 \mathrm{~s}$ ), we observe a sharp decrease in photocurrent, which indicates that the recombination rate increases quickly, prompting a fast return to the initial state which depends on the minority carriers' lifetime and is independent of the applied voltage.

\section{Conclusion}

The anodes used for the fabrication of flexible organic optoelectronic devices were developed with the goal of achieving optimal electrical and optical characteristics using mild deposition and annealing conditions that are dictated by the plastic substrate with IBS being an appropriate technique for this study. Furthermore, compatibility between the anode material and the substrate is an important parameter that needs to be taken into account. Our detailed study, which is presented here partially, indicates that a progress in the right direction has been made but further development is needed, and other transparent and robust high temperature polymeric substrates need to be investigated. On the device level, we have demonstrated that characteristics of the bulk heterojunctions can be improved by the use of our tri-layer anodes. Due to these optimized electrodes deposited on a flexible substrate, a power conversion efficiency of $2 \%$ was achieved. This result is comparable to the state-of-the-art flexible P3HT: PCBM-based devices. However, because of the important role of the transparent anode in photovoltaic devices, further work is required to reach the efficiencies attained by the same devices fabricated on glass substrates (efficiency higher than 6\%) [16, 17]. As for the phototransistor, where the role of the 
anode is less important than in photovoltaics, device characteristics are almost similar to those fabricated on glass. The phototransistor performance under UV illumination is due to the high photosensitivity of $1.510^{3}$ with a ratio of photocurrent to dark current of approximately $2.10^{3}$ at Vgs $=0 \mathrm{~V}$ (or $2.10^{4}$ in the sub-threshold regime). These results are in agreement with the literature and indicate that such transistors can be potentially used in photodetectors or amplifiers ordered by an optical gate. Therefore, any improvement in the flexible anode characteristics would certainly be a step in the right direction for the various organic optoelectronic devices.

\section{References}

1. V.Craciun, D. Craciun, Z.Chen, J. Hwang, R.K. Singh, Appl. Surf. Sci. 68, 118 (2000)

2. F.O. Adurodija, H. Izumi, T. Ishihara, H. Yoshioka, H. Matsui, M. Motoyama, Vacuum 59, $641(2000)$

3. W.F. Wu, B.S. Chiou, Semicon. Sci. Technol. 11, 1317 (1996)

4. L.J. Meng, A. Maçarico, R. Martins, Vacuum 46, 673 (1995)

5. D.Kim, Y. Han, J.S. Cho, S.K.Koh, Thin Solid Films 377, 81 (2000)

6. D.-F. Lii, J.-L. Huang, I.-J. Jen, S.-S. Lin, P. Sajgalik, Surf. Coat. Tech. 192, 106 (2005)

7. Y.Suzaki, T.Shikama, Electronics and communication in Japan 82, 30 (1999)

8. B. Lucas, A. El Amrani, A. Moliton, M. Dilhan, Superlattices and Microstructures 42, 357 (2007)

9. E. Fortunato, A. Gonçalves, C. Nunes de-Carvalho, A. Pimentel, G. Lavareda, A. Marques, R. Martins, Mat. Res. Soc. Sym. Proc. 814, 231 (2004)

10. E. Fortunato, M. H. Godinho, H. Santos, A. Marques, V. Assunçao, L. Pereira, H. Aguas, I. Ferreira, R. Martins, Thin Solid films 442, 127 (2003)

11. K.H. Choi, J.Y. Kim, Y.S. Lee, H.J. Kim, Thin Solid Films 341,152 (1999)

12. S.-S. Sun and N. S. Sariciftci, Organic Photovoltaics: Mechanisms, Materials, and Devices, Taylor \& Francis, London, (2005)

13. C. Yu, J. Gao, J. C. Hummelen, F. Wuld and A. J. Heeger, Science 270, 1789 (1995)

14. F. Padinger, R.S. Ritterberger, N.S. Sariciftci, Adv. Funct. Mater. 13, 85 (2003)

15. L.J.A. Koster, V.D Mihailetchi, P.W.M. Blom, Appl. Phys. Lett. 88, 093511 (2006)

16. K. Kim, J. Liu, M. A. G. Namboothiry, D. L. Carroll, Appl. Phys. Lett. 90, 163511 (2007)

17. H. Y. Chen, J. Hou, S. Zhang, Y. Liang, G. Yang, Y. Yang, L. Yu, Y. Wu, G. Li, Nature Photonics 3, 649 (2009)

18. M.C. Hamilton, S. Martin, J. Kanicki, IEEE Trans. Electron Devices 51, 877 (2004)

19. Y. Y. Noh, D. Y. Kim, Y. Yoshida, K. Yase, B. J. Jung, E. Lim, H. K. Shim, Appl. Phys. Lett. 86, 043501 (2005)

20. Q. Tang, L. Li, Y. Song, Y. Liu, H. Li, W. Xu, Y. Liu, W. Hu, and D. Zhu, Adv. Mater. 19, 2624 (2007) 
21. D. S. Chung, W. M. Yun, S. Nam, S. H. Kim, C. E. Park, J. W. Park, S.-K. Know, Y.-H. Kim, Appl. Phys. Lett. 94, 043303 (2009)

22. J.-H. Kwon, S.-I. Shin, C.-H. Kim, I.-K. You, G.-I. Cho, B.-K. Ju, J. Korean Phys. Soc. 55, 72 (2009)

23. B. Lucas, W. Rammal, A. Moliton, EUR. Phys. J. Appl. Phys. 34, 179 (2006)

24. S. Miller, G. Fanchini, Y.Y Lin, V. Li, C.W. Chen, W.F. Su, M. Chhowalla, J. Mater. Chem. 18, 306 (2008)

25. Y. Zhao, Z. Xie, Y. Qu, Y. Geng, L. Wang, Appl. Phys. Lett . 90, 043504 (2007)

26. A. Bedeloglu, A. Demir, Y. Bozkurt, N.S. Sariciftci, Synth. Met. 159, 2043 (2009)

27. A. Salleo, R.A. Street, Phys. Rev. B 70, 235324 (2004)

28. G. Horowitz, J. Mater. Chem. 9, 2001(1999)

29. M. Mas-Torrent, P. Hadley, N. Crivillers, J. Veciana, C. Rovira, ChemPhysChem 7, 86 (2006) 
Figure 1: $\mathrm{J}(\mathrm{V})$ characteristics under $100 \mathrm{~mW} / \mathrm{cm}^{2}$ illumination of (anode /PEDOT-PSS(30nm) /P3HT(24mg)-P3HT(30mg)/Al) solar cells on a PPC substrate.

Figure 2: IPCE spectra of P3HT: PCBM solar cells and optical transmission spectra of ITO(150nm) and ITO(70nm)/Ag(14nm)/ITO(70nm) anodes on a PPC substrate.

Figure 3: $I_{d s}-V_{d s}$ output characteristics for $V_{g s}$ varying from $-20 \mathrm{~V}$ to $-50 \mathrm{~V}$, obtained from a flexible pentacene-based OTFT tested in the dark. The inset represents a schematic cross section of the transistor.

Figure 4: (a) $\sqrt{-I_{d s}}-V_{\text {gs }}$ transfer characteristics for $V_{d s}=-30 \quad V$ obtained from a flexible pentacene-based OTFT tested in the dark and under illumination at $365 \mathrm{~nm}$.

(b) $\log \left(-\mathrm{I}_{\mathrm{ds}}\right)-\mathrm{V}_{\mathrm{gs}}$ plots for $\mathrm{V}_{\mathrm{ds}}=-30 \mathrm{~V}$ obtained from a flexible pentacene-based OTFT tested in the dark and under illumination at $365 \mathrm{~nm}$.

Figure 5: Photosensitivity of the flexible pentacene-based OTFT versus $V_{g s}\left(V_{d s}=-30 \mathrm{~V}\right)$.

Figure 6: Response times of the photocurrent for various bias voltages $\left(\mathrm{V}_{\mathrm{ds}}\right.$ varying from $-30 \mathrm{~V}$ to $-200 \mathrm{~V}$ ) and $\mathrm{V}_{\mathrm{gs}}=0 \mathrm{~V}$; note illumination $\mathrm{ON}$ and OFF positions. 
Table 1: Optical transmission and sheet resistance of ITO and ITO/Ag/ITO tri-layer structure deposited on flexible substrates (PPC or PET).

Table 2: Photovoltaic parameters for the various organic solar cells extracted from J(V) characteristics of Figure 1 under illumination.

\begin{tabular}{|l|c|c|}
\hline \multicolumn{1}{|c|}{ Flexible anodes } & $\begin{array}{c}\text { Sheet resistance } \\
(\boldsymbol{\Omega} / \square)\end{array}$ & $\begin{array}{c}\text { Transmittance at 550nm } \\
(\mathbf{\%})\end{array}$ \\
\hline PET/ ITO $(150 \mathrm{~nm})$ & 90 & 70 \\
\hline PPC/ ITO $(150 \mathrm{~nm})$ & 145 & 80 \\
\hline PPC/ ITO $(70 \mathrm{~nm}) /$ ITO $(14 \mathrm{~nm}) / \mathrm{ITO}(70 \mathrm{~nm})$ & 6.5 & 68 \\
\hline
\end{tabular}

Table 1

\begin{tabular}{|c|c|c|c|c|c|c|c|c|}
\hline Flexible anodes & $\begin{array}{c}\mathbf{R} \square \\
(\boldsymbol{\Omega} / \square)\end{array}$ & $\begin{array}{c}\mathbf{T r} \\
(\mathbf{\%})\end{array}$ & $\begin{array}{c}\mathbf{\eta e} \\
(\mathbf{\%})\end{array}$ & $\mathbf{F F}$ & $\begin{array}{c}\text { Voc } \\
(\mathbf{V})\end{array}$ & $\begin{array}{c}\mathbf{J}_{\text {SC }} \\
\left(\mathbf{m A} / \mathbf{c m}^{2}\right)\end{array}$ & $\begin{array}{c}\mathbf{R s} \\
(\mathbf{\Omega})\end{array}$ & $\begin{array}{c}\mathbf{R s h} \\
(\mathbf{\Omega})\end{array}$ \\
\hline PPC/ITO(150) & 145 & 80 & 0,48 & 0,35 & 0,39 & 3,33 & 328 & 859 \\
\hline PPC/ITO(70)-Ag(14)-ITO(70) & 6,5 & 68 & 2 & 0,39 & 0,51 & 9,58 & 127 & 1381 \\
\hline
\end{tabular}

Table 2 


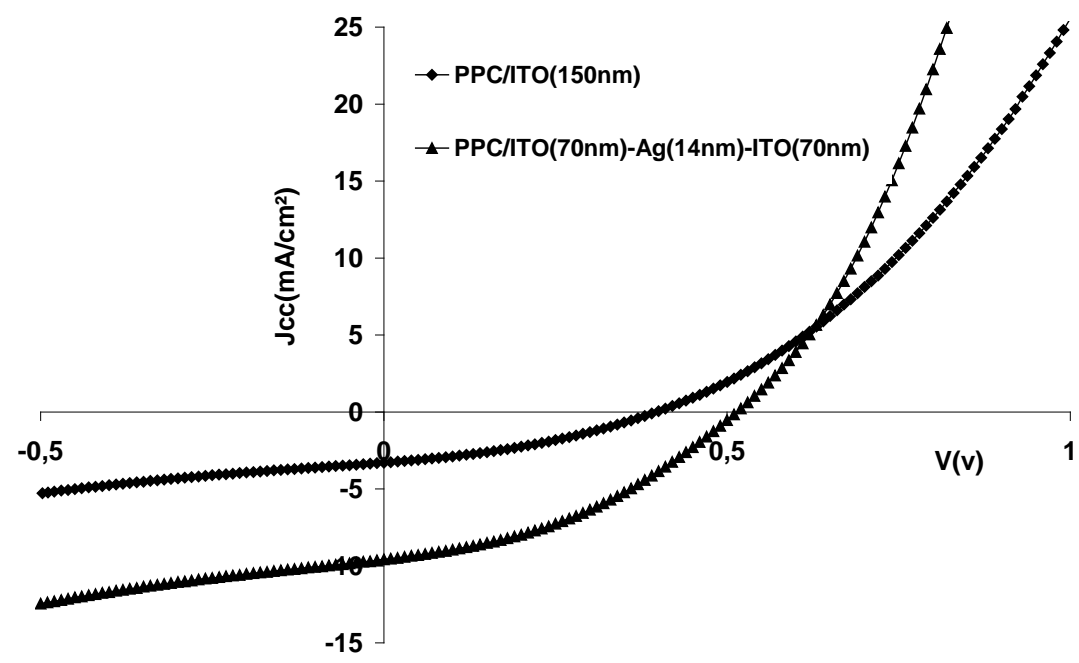

Figure 1 


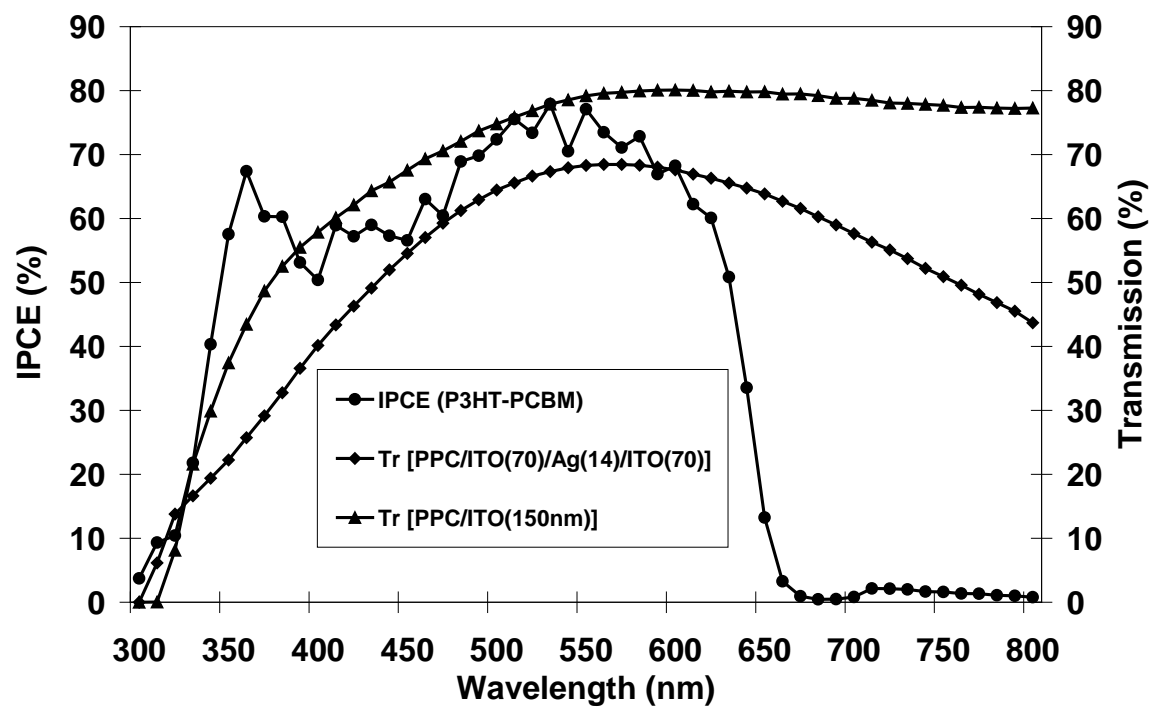

Figure 2 


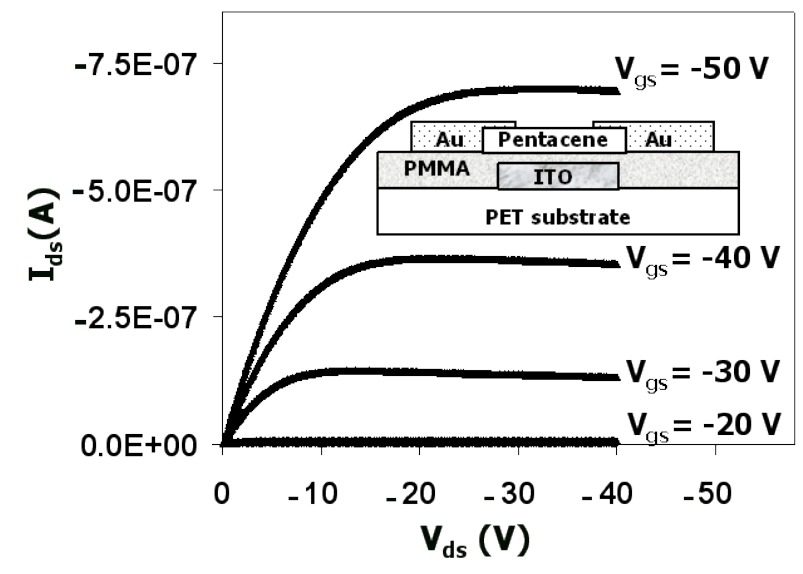

Figure 3 

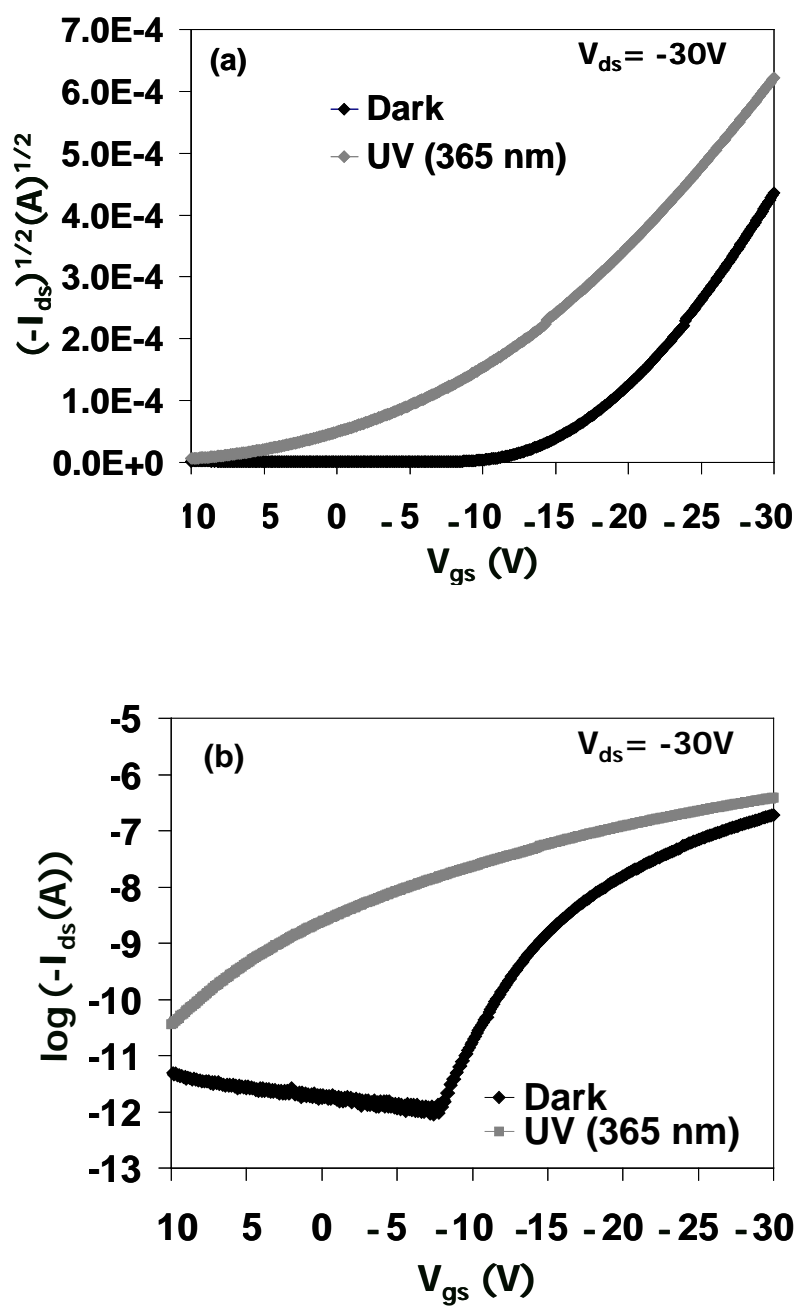

Figure 4 


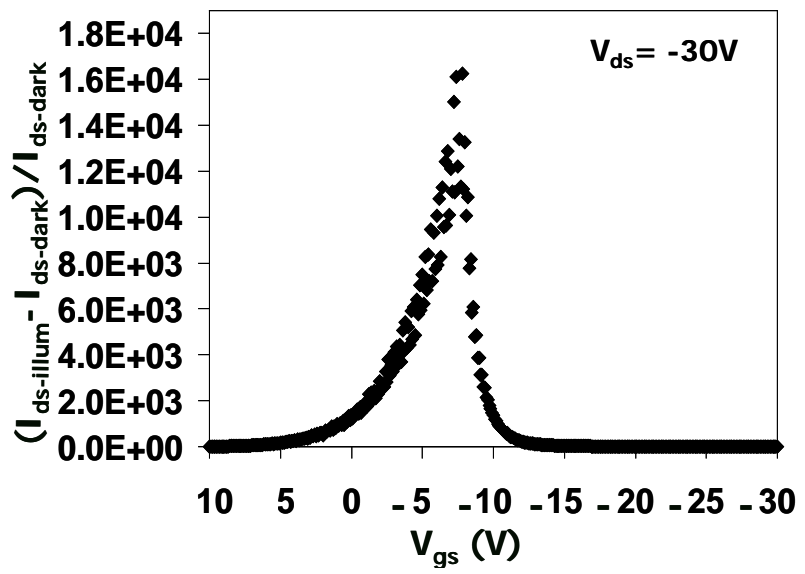

Figure 5 


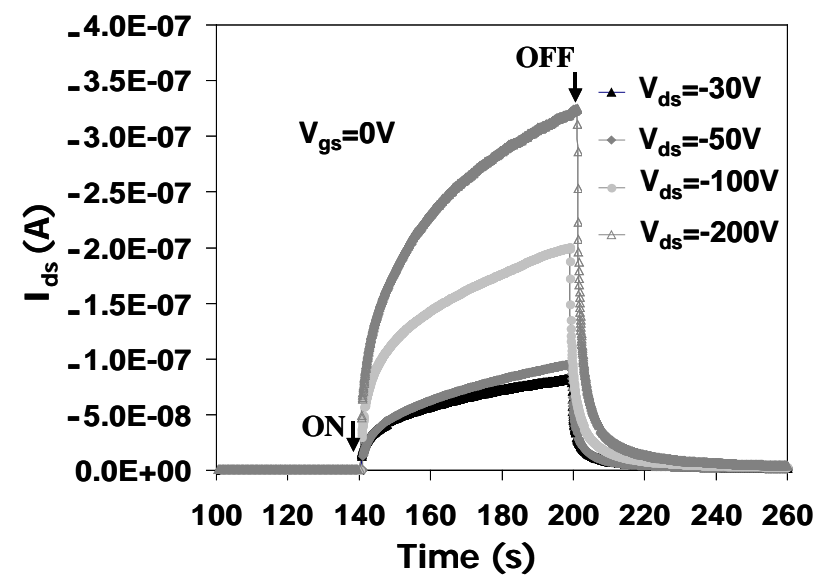

Figure 6 